\title{
Processos de saúde e doença entre crianças institucionalizadas: uma visão ecológica
}

\author{
$H$ ealth and disease processes among institutionalized children: \\ an ecological vision
}

\begin{abstract}
Lília I êda Chaves Cavalcante ${ }^{1}$
Celina M aria Colino $M$ agalhães ${ }^{2}$

Fernando Augusto Ramos Pontes ${ }^{2}$
\end{abstract}

${ }^{1}$ Departamento dePolíticas eTrabalhos Sociais, UniversidadeFederal do

Pará. AvenidaAugusto Correa 1, Guamá.

66075-900 Belém PA.

lilia.cavalcante@uol.com.br

${ }^{2}$ Departamento de

Psicologia Experimental

ePrograma de Pós-

Graduação em Teoriae

Pesquisa do

Comportamento,

UniversidadeFederal do

Pará.
Abstract This article discusses aspects of health and disease processes among children attended in a child shelter of the city of Belém between 2004 and 2005. Thedata were collected from documental sourcesand through interviews with technicians of the institution. From a total of 287 children, $49.47 \%$ presented diseases, deficiencies and injuries when being admitted to the shelter, probably associated to the situation of poverty and negligence they were exposed to since they wereborn. During their permanencein theshelter, it was verified that the children contracted infecto-contagiousdiseases $(42.5 \%)$ and manifested problems of emotional nature $(18.83 \%)$ that can be related to the environmental characteristic of the institution - inadequateproportion adult/children (1:8) and overcrowding (75/month). Theresultsallow concluding that the children's health conditions reflect the situation of material and emotional privation to which they were exposed when living with the family and during their permanence in the shelter. In this sense, the health and disease processes are discussed from an ecological perspective that recognizes the biological, social and cultural factors that constitute the family and the shelter as developmental contexts of the institutionalized child.

Key words Institutionalized child, Shelter, Health, Disease, Infantile devel opment
Resumo Este artigo discute aspectos do processo de saúdee doença entrecrianças assistidas em um abrigo infantil de Belém, entre 2004 a 2005. Os dados foram coletados em fontes documentais epor meio de entrevista com técnicos da instituição. De um total de 287 crianças, constatou-se que $49,47 \%$ apresentavam doenças, deficiências elesões corporais quando do seu encaminhamento ao abrigo, quepodem ser associadas à situação de pobreza en egligência familiar experimentadas desde o nascimento. Em relação ao período de permanência na instituição, verificou-se que as crianças contraíram doenças infectocontagiosas $(42,5 \%)$ e manifestaram problemas de ordem emocional ( $18,83 \%)$, quepodem estar relacionados às características ambientais da instituição proporção adulto/criança inadequada (1:8), superlotação do espaço (75/mês). Os resultados permitem concluir quea condição de saúde das crianças traduz as situações de privação material e emocional a que foram submetidas no convívio com a família e ao longo de sua permanência no abrigo. N esses termos, os processos de saúde e doença são di scutidos a partir de uma perspectiva ecológica, que reconhece fatores biológicos, sociais eculturais que constituem a família e o abrigo como contextos de desenvolvimento da criança institucionalizada.

Palavras-chave Criança institucionalizada, Abrigo, Saúde, Doença, Desenvolvimento infantil 
Introdução

Em 2004, estudo realizado pelo Instituto de Pesquisa Econômica Aplicada (IPEA) sobre a situação dos abrigos infanto-juvenis no país constatou a existência de milhares de crianças que estão privadas dos cuidados parentais, distantes da família por longo período de tempo, configurando a chamada infância de risco ${ }^{1,2}$.

As razões que explicam esse fato provavelmente estão relacionadas ao agravamento de problemas estruturais da sociedade brasileira e aos desafios colocados às famílias na contemporaneidade, nos quais se inclui a reprodução intergeracional de um estilo parental permissivo, indiferente ou autoritário ${ }^{3}$, a incidência de acontecimentos estressantes como o desemprego crônico e a dissolução das relações conjugais ${ }^{4}$, a fragilidade da rede social de apoio no cumprimento das funções de sustento e educação dos filhos ${ }^{5}$.

Brazelton e Greenspan ${ }^{6}$ consideram queainfância representa um período especialmente favorável ao desenvolvimento de certas propriedades humanas. Para eles, quando a criança é submetida a situações de privação material eemocional severas, geradas ou não pela pobreza, esse potencial desenvolvimental podenão se realizar demaneira saudável e adequada, o que implica riscos ao processo de estruturação da personalidade, à construção da sociabilidade e ao amadurecimento psicológico.

As experiências que se processam na infância têm um peso diferenciado no ciclo vital humano e apontam em que direção pode caminhar o desenvolvimento, o que aumenta a importância de pesquisas que tomem como objeto de estudo os contextos de desenvolvimento da criança desde o início da vida.

Nesses termos, o contexto envolve todos e cada um dos ambientes em que a criança está crescendo, aprendendo e se desenvolvendo como pessoa ${ }^{7}$. Desse modo, a definição de contexto não contempla apenas o lugar físico ondea criança está situada, mas referese a ela mesma como indivíduo e suas particularidades, às pessoas com as quais interage e que também participam desse ambiente, aos processos pelos quais constroem e mantém relações sociais.

De acordo com Bronfenbrenner ${ }^{8}$, o conceito de contexto de desenvolvimento engloba tanto as condições físicas em que a criança realiza o seu viver como a rede de relações que definem a qualidade da convivência social nesses espaços. Do ponto de vista ecológico, a família, a escola, a creche, 0 abrigo, entre outras instituições infantis, seriam contextos de desenvolvimento da criança na primeira infância.
De maneira geral, a família é considerada o primeiro eo principal contexto de desenvolvimento da criança, justamente porque tem obrigações e responsabilidades bem específicas ao longo da trajetória de socialização da criança. Desse modo, é dever dos pais cumprir funções de sustento, educação e assistência aos filhos, procurando colocálos a salvo de qualquer forma de abandono, violência ou discriminação. Entretanto, a pobreza pode levar pais e outros cuidadores a fal har ou se omitir nessas tarefas. N essas circunstâncias, a experiência da convivência familiar tendea se realizar em um contexto marcado por uma série de privações que são decisivas para o bem-estar físico e emocional da criança.

Em função disso, a investigação de aspectos relacionados ao processo de saúde e doença em ambientes coletivos de cuidado ( como são os abrigos infantis, as creches e outras unidades de educação infantil), envolve necessariamente uma rede deelementos esignificações que compõem os contextos de desenvolvimento da criança institucionalizada, propiciando a integração de fatores explicativos de natureza orgânica, física, interacional, social, econômica e ideológica?.

Neste trabalho, nos moldes em que propôs Bronfenbrenner ${ }^{8}$, privilegiou-se o modelo ecológico do desenvolvimento humano para a análise de questões relacionadas à saúde infantil, perspectiva teórica a partir da qual doenças, distúrbios e deficiências são reconhecidascomo produto deumaconjunção de fatores que revela as múltiplas faces do ambientefísico esocial ondea criança institucionalizada realiza o seu viver, assim como traduz os padrões de cuidado infantil que estão presentes na família e no abrigo como contextos específicos.

A análise dos processos de saúde/doença em ambiente de abrigo requer uma postura de crítica às concepções mais simplistas e menos abrangentes acerca dos fatores de proteção e risco colocados ao bem-estar físico e emocional nos primeiros anos da infância, uma vez que, mesmo tendo sido entregue aos cuidados de uma instituição e afastada de seus pais e/ou responsáveis, a criança institucionalizada possui um legado biológico, social e cultural, uma origem familiar que precisa ser considerada nesse processo.

A literatura mostra que crianças institucionalizadas são oriundas geralmente de famílias com renda, moradia e escolaridade precárias, ficando expostas, por vezes desde o nascimento, a toda sorte de privações e maus-tratos nos primeiros seis anos de vida ${ }^{1,10}$.

Esses trabal hos indicam que a combinação explosiva entre pobreza, desagregação familiar econ- 
sumo abusivo de álcool e outras drogas por cuidadores primários tende a deteriorar as condições gerais de vida da população infantil, criando condições propícias ao descumprimento pelos pais da atenção mais elementar devida aos filhos: assegurar proteção contra qualquer forma de abandono eviolência.

Do ponto de vista da análise ecológica do desenvolvimento humano, contudo, não são apenas os fatores familiares que exercem influência direta sobre os processos de saúde/doença na primeira infância. Também a contínua ea longa permanência da criança em ambiente institucional pode se constituir em um importante fator de risco à saúdeinfantil, deixando-a particularmentevulnerável a doenças infecciosas e problemas dermatológi$\cos$, bem como à manifestação de diversos estados de depressão.

Em estudo sobre a questão, foi demonstrado que crianças na faixa-etária de 1 a 5 anos, que conviviam em ambientede cuidado coletivo entre doze e cinqüenta horas por semana, apresentavam três a cinco vezes mais chance de manifestar pelo menos dois sintomas de infecção respiratória (tosse, coriza, temperatura axilar $>38^{\circ} \mathrm{C}$, dispnéia) do que as que haviam sido cuidadas em casa por seus familiares ${ }^{11}$.

No caso específico das crianças que fazem do abrigo seu local de moradia, os resultados acima permitem supor que, quanto maior a quantidade de tempo passado sob os cuidado de uma instituição, maior o nível de exposição a agentes patogê nicos e situações de sofrimento psíquico.

No Brasil, a preocupação com a promoção da saúde em abrigos infantis encontra suas raízes nas medidas de higienização de instituições asilares e orfanatos deflagradas a partir do final do século XIX. N esse contexto, a introdução de práticas inspiradas no discurso médico-higienista valorizava a profilaxia de doenças físicas ( preven ção de mortes por infecções e epidemias), o combate ao abandono moral (recolhimento de crianças que viviam em meio à mendicância, à criminalidade, à promiscuidade, ao vício) e a intervenção nas "chagas sociais" (conservação de infantes e nascituros enjeitados), segundo observam Costa ${ }^{12}$ e Trindade ${ }^{13}$.

Para esses autores, ao longo dos séculos, muitas crianças institucionalizadas têm sido condenadas a viver em lugares atingidos por epidemias ou endemias, que propiciam a disseminação de doenças causadas por bactérias, vírus e parasitas, além defreqüentedescuido com a alimentação e a nutrição infantil.

Nos dias atuais, em que pese um melhor desempenho dos principais indicadores de saúde (mortalidade infantil, baixo peso ao nascimento, óbitos por doenças chamadas evitáveis), tanto na sociedade como quanto no interior das instituições, ainda são elevados os números de internações hospitalares e óbitos por infecções diarréicas e respiratórias.

Rutília ${ }^{14}$ investigou a incidência de desnutrição e doenças infecciosas entre crianças que foram internadas na Fundação Estadual do Menor (FEEM ), no Rio de Janeiro. 0 objetivo de seu estudo era discutir, a partir de aspectos biológicos, ecológicos, culturais e socioeconômicos, o estado geral de saúde e a incidência de doenças entre crianças institucionalizadas. A equipe procedeu a estudo minucioso de 38 casos de crianças falecidas no período de 1986 a 1988, na FEEM . O autor concluiu que os casos de desnutrição e infecção traduziram bem a combinação de fatores biológicos, afetivos esociais relacionados ao desenvolvimento da criança institucionalizada, ou seja, permitiram pensar a relação entre o indivíduo e o meio ambiente como um amplo e dinâmico sistema ecológico, ainda que essa investigação tenha sido prejudicada pela ausência de dados mais precisos sobre a qualidade do ambiente físico e social, antes e durante a permanência na instituição.

A partir de meados do século $X X$, pesquisas chamam a atenção do mundo e da comunidade científica quanto aos efeitos da institucionalização precoce e prolongada para a saúde mental, na medida em quea longa exposição da criança ao cuidado compartilhado e coletivizado cria condições favoráveis à manifestação de distúrbios psicológicos e outras formas de sofrimento psíquico ${ }^{8,15-17}$.

Para esses pesquisadores, em qualquer idade, a institucionalização é descrita como uma experiência humana difícil sob vários aspectos. Entretanto, nos primeiros anos de vida, as seqüelas emocionais, sócio-afetivas, são tidas como mais graves, porque a criança é afastada do seu ambiente natural, é levada a conviver de modo intenso com pessoas e situações estranhas, é privada de aten ção exclusiva e atendimento individualizado.

0 presente trabalho tem por objetivo colocar em discussão um conjunto de dados sobre a saúde de 287 crianças que foram acolhidas ecuidadas em um abrigo infantil situado na Região M etropolitana de Belém, a partir da análise integrada de descritores relacionados às condições gerais do nascimento evida em família, às doenças mais freqüentes e às situações de sofrimento físico e emocional a partir do ingresso na instituição.

A análise de cada uma das variáveis propostas permite compreen der aspectos particulares da saúde dessa população e reconhecer pontos de inter- 
secção entre as condições gerais de nascimento e convivência na família de origem eas características ambientais que são próprias do modo de vida em instituições decuidado infantil. Para tanto, privilegia-se, neste estudo, a compreensão ecológica dos processos de saúde e doença em ambiente coletivo de cuidado infantil, assim como a análise da conjunção de fatores que delimitam as circunstâncias de risco à saúde experimentadas pel as crianças, seja no contexto familiar seja no ambienteinstitucional.

\section{M étodo}

\section{Informantes}

Uma equipe formada por cinco profissionais, todos funcionários do abrigo há pelo menos dois anos, sendo dois assistentes sociais, uma psicóloga, uma pedagoga e uma enfermeira, forneceu informações relativas a 287 crianças que foram acoIhidas em uma instituição de abrigo, entre os anos de 2004 e 2005.

\section{Ambiente}

A instituição pesquisada é considerada o maior abrigo infantil do Estado do Pará e está situada na Região M etropolitana deBelém. Desdesua fundação, em 1993, a instituição é responsável pelo acolhimento de crianças, na faixa etária de 0 a 6 anos, em situação de risco social e pessoal, conforme define o Estatuto da Criança e do Adolescente. A média de atendimento por mês gira em torno de 75 abrigados, ainda que tantas vezes cheguea acoIher até noventa crianças.

\section{Instrumento e materiais}

Foi utilizado um formulário elaborado com base em estudo anterior sobre a condição psicossocial de crianças que viviam em abrigos einstituições similares desenvolvido por Weber e Kossobu$\mathrm{dzki}{ }^{18}$. N esse sentido, foram suprimidas, alteradas ou incluídas novas perguntas, adequando 0 instrumento às particularidades do universo empírico presentes neste estudo.

0 instrumento foi composto majoritariamente por perguntas estruturadas e com múltiplas alternativas de resposta, organizadas em torno dos se guintes eixos: identificação pessoal (dez itens), estruturafamiliar (dezenoveitens), histórico deinstitucionalização (trinta itens), situação sociojurídica atual (dezenoveitens) esaúde da criança (dezesseisitens) sendo este último objeto de análise deste trabalho.
A consulta foi feita diretamente em fontes documentais (relatórios, pareceres, laudos, prontuários, certidões), assim como por meio de entrevista semi-estruturada com profissionais dispostos a colaborar com informações sobre aspectos relevantes da trajetória de encaminhamento, acolhimento e cuidado de cada uma das crianças pela instituição.

N essa fase da pesquisa, éinteressante destacar a consulta aos seguintes documentos: estudo social (dados sobre a composição familiar, condições de moradia, perfil dos pais e/ou responsáveis), declaração de nascidos vivos (informações sobre a gestação, a parturiente, o parto, as características do recém-nascido), prontuário médico (anotações sobre condição geral de saúde ao ingresso no abrigo e ao longo da sua permanência) e termo de encaminhamento do consel ho tutelar (relatos sobrea condição sociojurídica da criança).

\section{Procedimento}

0 estudo teveinício com o pedido deautorização ao titular da Vara da Infância e Juventude do Tribunal de Justiça do Estado do Pará para a realização da pesquisa nas dependências da instituição selecionada, no sentido de favorecer 0 acesso aos profissionais e aos documentos que registravam aspectos da história de vida e condição sociojurídica dos abrigados. Também a proposta de estudo foi submetida à apreciação do Comitê de Ética para Pesquisas com Seres Humanos da Universi dade Federal do Pará, cuja aprovação foi feita sem restrições ou recomendações especiais.

No abrigo, foram feitos contatos iniciais e reunião com a equipe técnica para apresentar os objetivos e o método da pesquisa e motivar a colaboração de todos com as informações e os esclarecimentos necessários.

Após essa reunião, foi realizada a seleção do material a ser utilizado pela pesquisa a partir de critérios como legitimidade(priorizou-sedocumentos oficiais) e confiabilidade (rejeitou-se certidões com rasuras ou ilegíveis e anotações informais). Esse procedimento assegurou a formação de uma base de dados com boa margem de fidedignidade, na medida em que a possibilidade de comparar registros disponíveis em mais de uma fonte permitiu aos pesquisadores identificar lacunas e contornar problemas esperados, como a dispersão de dados e a imprecisão de informações contidas em relatórios elaborados por técnicos da instituição.

À medida que os documentos foram examinados, as informações foram registradas em um formulário elaborado especificamente para esse fim. 
Em seguida, foi feita a consulta a membros da equipetécnica do abrigo no sentido decomplementar e/ ou validar as informações solicitadas por meio de entrevista.

A definição das variáveis, categorias eunidades de análise utilizadas neste estudo orientou a transcrição e a organização dos dados e posteriormente o tratamento estatístico desse material por meio de planilhas eletrônicas, construídas pelo programa Excel, da M icrosoft. Ao final, o sistema deapresentação dos resultados obtidos foi estruturado em torno das seguintes unidades de análise: tipo de parto, prematuridade, peso ao nascer, aleitamento materno, distúrbios no desenvolvimento, deficiência, lesão corporal e doenças apresentadas à entrada no abrigo, problemas de saúde registrados durante a sua permanência no espaço, bem como dificuldades de adaptação à vida institucional.

\section{Resultadosediscussão}

De início, é oportuno registrar que a ausência de informações precisas sobre aspectos investigados foi uma constante ao longo de todo o processo de coleta de dados. Entretanto, essa dificuldade foi mais sentida em relação às seguintes variáveis: características do parto, al eitamento materno, cobertura vacinal e indicadores do crescimento físico da criança.

No cômputo geral, foram analisados 287 casos de crianças acolhidas pela instituição; porém, cabe salientar queem al gumas situações não havia informações pormenorizadas sobre a origem familiar e a condição de saúde da população de abrigados. É o caso, por exemplo, das crianças abandonadasainda na maternidade, das quais a instituição não dispunha de referências claras quanto à identidade de pais biológicos. Ou ainda, nas situações em que o período de abrigamento não ultrapassou a marca das 72 horas, fato que costuma deixar profissionais e autoridades bem à vontade para registrar apenas as informações que consideram indispensáveis à conclusão do ciclo de atendimento.

De qualquer modo, como nem sempre as informações desejadas estavam disponíveis para consulta e exame, os procedimentos da pesquisa precisaram ser alterados e os percentuais relativos a cada categoria tomaram como referência apenas o número de crianças que dispunham de registros atualizados e seguros em seus prontuários e/ou demais documentos apresentados pela institui ção.

Essa é a situação dos resultados que descrevem a freqüência de variáveis relacionadas às condições em que ocorreu a gestação e o nascimento das cri- anças envolvidas na pesquisa. Os resultados obtidos permitem concluir que, no universo dos casos analisados ( $n=41$ ), a maioria das crianças nasceu por meio de parto normal $(70,73 \%)$, ainda que 0 percentual relativo a parto operatório tenha sido significativo (29,27\%). Já em relação à incidência de prematuridade nessa população, em $45,72 \%$ dos casos levantados $(n=35)$ havia registro de parto prétermo (a criança nascera antes de completar 37 semanas de gestação), embora $54,28 \%$ desse total representem nascimentos havidos no período considerado a termo (entre 37 e 41 semanas).

Entre os casos que apresentavam alguma informação sobre intercorrências havidas no parto ( $n=32$ ), em $43,75 \%$ desse total existiam o registro de situações que colocaram em risco a vida e o estado geral de saúde da criança quando recémnascida: icterícia e infecção neonatal, desconforto respiratório, sífilis congênita, entre outras síndromes não especificadas nos registros oficiais.

No que se refere ao peso à hora do nascimento, os resultados obtidos indicam que $40,62 \%$ do total considerado ( $\mathrm{n}=32$ ) pesavam menos de $2.500 \mathrm{~g}$. Esse dado é importante porque a prematuridade e o baixo peso têm sido reconhecidos como fatores de risco para situações de abandono de bebês enegligência familiar. A permanência de crianças nos primeiros dias e meses de vida em instituições de abrigo ainda éjustificada muitas vezes em razão de fatores biológicos. Nas situações em que o bebê nasce de parto considerado pré-termo ecom baixo peso, os cuidados com a sua saúde precisam ser redobrados enem sempre os pais e demais familiares estão preparados para assumir essa responsabilidade, como analisa M otta ${ }^{19}$.

No que tange ao número de crianças que não foram alimentadas com leite materno, esse percentual representa $54,05 \%$ do total de casos em que essa informação estava disponível $(n=37)$. Isso significa que, na maioria das vezes, não havia qualquer anotação a respeito da questão, mesmo em situações nas quais a criança estava sob os cuidados da instituição desde os primeiros dias e meses de vida.

Este estudo levantou também a incidência de crianças portadoras de necessidades especiais. Em $91,45 \%$ do total de casos analisados ( $n=199$ ), não foram encontrados registros de qualquer tipo de distúrbio no processo de desenvolvimento da fala ou limitações de ordem auditiva ou visual. Contudo, em 8,02\% dos casos, as crianças apresentavam distúrbios diversos, ora relacionados à fala e à linguagem $(4,51 \%)$, ora à perda da capacidade visual motivada por estrabismo, baixa visão e retinopatia $(3,51 \%)$. 
Quanto ao número de crianças portadoras de algum tipo de deficiência, constatou-se que, no universo considerado ( $n=199$ ), cerca de $93,96 \%$ não possuem comprometimento intelectual e/ou limitações do comportamento adaptativo que tenham resultado em prejuízos à independência na locomoção, à aquisição de habilidades sociais, ao desempenho acadêmico, como entendem Papalia e Olds $^{20}$. Por seu turno, verificou-se que, nesse mesmo universo, 5,02\% das crianças são portadoras de deficiências que afetaram em diferentes níveis o seu desenvolvimento psicomotor. Essepercentual foi organizado em torno de duas categorias: paralisia de membros ou partes do corpo, com movimentos limitados e/ou rígidos $(3,01 \%)$ e limitações múltiplas decorrentes de doen ças congê nitas como a hidrocefalia (2,01\%).

0 estudo também investigou as evidências empíricas de uma realidade não menos preocupanteà saúde infantil - física e mental. Os resultados obtidos revelam que $7,66 \%$ das 287 crianças, ao darem entrada na instituição, traziam consigo as marcas visíveis da violência intrafamiliar: hematomas (inchaços, áreas escurecidas e intumescida por sangue extravasado), ferimentos (arranhões, cortes, ulcerações, cicatrizes), queimaduras (feridas nas mãos e outras partes do corpo), manipulação de órgãos genitais. Nesses casos, é preciso esclarecer que as evidências de maus-tratos foram registradas por profissionais de saúde que, após procederem à avaliação geral do estado físico eemocional da criança, constataram a presença de vários tipos de lesões no rosto e outras partes do corpo.

N esse contexto, é importante ressaltar que em $92,33 \%$ dos casos não havia o registro claro de que a criança apresentava qualquer tipo de lesão corporal quando da sua chegada ao abrigo, ou seja, não foram observadas lesões graves ou superficiais na superfície da pele e couro cabeludo. No entanto, 7,67\% apresentavam algum tipo de lesão física, como mostra a Tabela 1.

Tabela 1. Distribuição de crianças conforme registro de lesão corporal à entrada no abrigo.

\begin{tabular}{lcc}
\hline \multicolumn{1}{c}{ Lesão corporal } & Freqüência & $\%$ \\
\hline Não apresentavam qualquer & 265 & 92,33 \\
tipo de lesão corporal & 15 & 5,24 \\
Ferimentos & 04 & 1,39 \\
Hematomas & 02 & 0,69 \\
Queimaduras & 01 & 0,35 \\
Sinais de manipulação do pênis & 287 & 100 \\
Total & \\
\hline
\end{tabular}

Os resultados da Tabela 1 indicam que crianças ainda são afastadas do convívio com seus pais e/ou responsáveis por motivo tão antigo quanto atual: 0 uso da punição física pela família como mecanismo disciplinar. Por isso, fatos dessa natureza têm preocupado especialistas em saúde infantil do mundo inteiro, já que os castigos físicos corriqueiros têm se constituído na porta de entrada para formas mais severas de agressão física às crianças, que podem resultar em mortes, mutilações, doenças, incapacidades físicas e mentais.

Com relação ao número decrianças quejáapresentavam graves problemas de saúde no momento em que foram encaminhadas ao abrigo, ora doenças congênitas (cardiopatias, hidrocefalias), ora adquiridas no período de convivência com a família (doenças infecciosas, verminoses, viroses), observa-se que representam quase a metade da população considerada. Isso significa que $49,47 \%$ das crianças apresentavam algum problema de saúde (doença, síndrome, deficiência ou alteração nutricional) no exato momento em que davam entrada na instituição. Entre as demais, constatou-se que essa informação não estava disponível $(41,82 \%)$ ou mesmo havia o registro que criança apresentava boas condições de saúde (8,71\%).

A Tabela 2 mostra que as doenças com maior incidência entre as crianças foram escabiose $(19,51 \%)$, gripe/resfriado $(10,80 \%)$, desnutrição $(10,45 \%)$, dermatite $(8,01 \%)$, anemia $(5,57 \%)$ e pediculose $(4,18 \%)$. Para esses cálculos, considerou-se o número de menções à doença nos registros institucionais, ora citada de modo exclusivo ou associada a outras moléstias.

Os resultados apresentados permitem afirmar que os problemas de saúde mais freqüentes entre as crianças no momento em que deram entrada na instituição são justamente aquel es relacionados às condições adversas impostas pela condição de pobreza e à qualidade do cuidado que lhes foi oferecido desde o nascimento, em que se inclui a alimentação insuficiente e/ou inadequada à idade, a desatenção com a higiene corporal e ambiental, 0 desmame precoce, o descumprimento dos programas de imunização.

Por sua vez, quando se procede à análise dos dados referentes à incidência dessas e de outras doenças na população selecionada, constata-seque $42,51 \%$ do número total de crianças com participação na pesquisa apresentaram problemas de saúde diversos ao longo da sua permanência no abrigo. Entretanto, torna-se importante ressaltar que esse percentual pode ser inclusive maior, uma vez que, em muitos casos, essa informação simplesmente não estava disponível para consulta 
(48,78\%), na medida em que as anotações sobre o quadro geral de saúde costumam ser eliminadas tão logo ocorra o retorno da criança ao convívio com seus pais ou, mesmo, a sua adoção por outra família. Hátambém um percentual de crianças que declaradamente não apresentou nenhum problema de saúde no período em que durou o seu acoIhimento pela instituição (8,71\%).

A partir da análise dos dados coletados, observou-se que, entre as doenças que foram citadas um maior número vezes nos registros oficiais, encontram-se a gripe/resfriado (32,40\%), a diarréia (12,54\%), a bronquite/asma (6,62\%), a pneumonia (5,22\%), a escabiose ( $4,52 \%)$ e a otite (3,83\%) (Tabela 3).

Pelo exposto, verifica-se que, ao contrário dos problemas de saúde remanescentes do período de convivência da criança em ambientefamiliar, quase sempre relacionados à mán nutrição eà falta dehigiene dos cuidadores primários ${ }^{21}$, as doenças infecciosas e/ou transmitidas por contato foram os males

Tabela 2. Distribuição das crianças segundo doenças e problemas de saúde que apresentavam quando do encaminhamento e acolhimento pelo abrigo.

\begin{tabular}{|c|c|c|}
\hline $\begin{array}{l}\text { Doenças e problemas de saúde } \\
\text { apresentados à entrada no abrigo }\end{array}$ & Freqüência & $\%$ \\
\hline Escabiose & 56 & 19,51 \\
\hline Gripe/resfriado & 31 & 10,80 \\
\hline Desnutrição & 30 & 10,45 \\
\hline Dermatite & 23 & 8,01 \\
\hline Anemia & 16 & 5,57 \\
\hline Pediculose & 12 & 4,18 \\
\hline I cterícia & 07 & 2,43 \\
\hline Bronquite/asma & 07 & 2,43 \\
\hline Pneumonia & 05 & 1,74 \\
\hline Diarréia & 05 & 1,74 \\
\hline Seborréia & 04 & 1,39 \\
\hline Otite & 04 & 1,39 \\
\hline Hidrocefalia & 04 & 1,39 \\
\hline Alergia & 04 & 1,39 \\
\hline Infecção neonatal & 03 & 1,04 \\
\hline Furunculose & 03 & 1,04 \\
\hline Verminose & 02 & 0,69 \\
\hline Nódulos, cistos & 02 & 0,69 \\
\hline Impetigo & 02 & 0,69 \\
\hline Cáries dentárias & 02 & 0,69 \\
\hline $\begin{array}{l}\text { Outros (sífilis, portadora do vírus } \\
\text { HIV, meningomielocele, hidrocele, } \\
\text { hérnia umbilical, conjuntivite, } \\
\text { catarata congênita, broncodisplasia) }\end{array}$ & 13 & 4,54 \\
\hline
\end{tabular}

mais comuns entre os abrigados, provavelmente em razão do convívio intenso em grupos de pares e à completa ausência de espaço individualizado na instituição. A elevada incidência de doenças infectocontagiosas nessa população pode estar relacionada às privações típicas da convivência em ambientesinstitucionais, ondeo cuidado infantil écoletivo e há compartilhamento contínuo de ambientes e objetos pessoais (louças, roupas, brinquedos, toaIhas, material de higiene, entre outros) ${ }^{7,22}$.

Entre os resultados obtidos, verificou-se ainda que o distanciamento da família e permanência no abrigo, mesmo quando não prolongada, com fre qüência provocou em várias crianças uma série de alterações em seu estado físico e emocional (humor, sono, apetite, concentração, atividade), sobretudo no período imediatamente posterior ao seu ingresso na instituição.

A Tabela 4 mostra que $18,83 \%$ das crianças esboçaram diferentes formas de reação às situações novas e estranhas que Ihes foram apresentadas no ambienteinstitucional. Entreas situações maiscomuns, $8,71 \%$ correspondem a episódios de choro intenso e/ou contínuo, 5,92\% referem-se a comportamento agressivo da criança em relação a seus cuidadores e pares, $6,95 \%$ dizem respeito a atitudes que expressam retraimento social e/ou timidez excessiva.

N esse contexto, é importante registrar que em $81,17 \%$ dos casos analisados não havia registro de

Tabela 3. Distribuição das crianças segundo doenças e problemas de saúde apresentados ao longo do tempo em que permaneceram sob os cuidados da instituição de abrigo.

$$
\text { Doenças e problemas de saúde Freqüência \% }
$$
apresentados no abrigo

\begin{tabular}{lrr}
\hline Gripe/resfriado & 93 & 32,40 \\
Diarréia & 36 & 12,54 \\
Bronquite/asma & 19 & 6,62 \\
Pneumonia & 15 & 5,22 \\
Escabiose & 13 & 4,52 \\
Otite & 11 & 3,83 \\
Dermatite & 08 & 2,78 \\
Anemia & 08 & 2,78 \\
Desnutrição & 06 & 2,09 \\
Pediculose & 04 & 1,39 \\
Amidalite & 04 & 1,39 \\
Outras doenças (alergias, & 10 & 3,49
\end{tabular}

furunculose, verminose, infecção

urinária, hérnia) 
Tabela 4. Distribuição de crianças segundo dificuldades apresentadas no período de adaptação à vida no abrigo.

\begin{tabular}{lcc}
\hline \multicolumn{1}{c}{$\begin{array}{c}\text { Dificuldade de adaptação } \\
\text { à vida no abrigo }\end{array}$} & Freqüência & $\%$ \\
\hline Choro intenso e/ou contínuo & 25 & 8,71 \\
Retraimento + timidez excessiva & 20 & 6,95 \\
+ solidão + introversão & & \\
Agressividade & 17 & 5,92 \\
Atividade excessiva + hiperatividade & 08 & 3,12 \\
Sensação de medo constante & 06 & 2,09 \\
Dificuldade para se comunicar & 05 & 1,74 \\
+ fala pouco & & \\
Recusa de alimentos & 03 & 1,04 \\
Desobediência + rebeldia & 03 & 1,04 \\
Expressão de tristeza + apatia & 03 & 1,04 \\
Dificuldade de concentração & 02 & 0,69 \\
Outros (ansiedade, apatia, & 05 & 1,75 \\
comportamento sexual inadequado & & \\
para a idade) & & \\
& &
\end{tabular}

alterações de ordem física e emocional no estado geral da criança recém-abrigada. Em outras palavras, a maioria das crianças não apresentou alterações graves no humor, na qualidade do sono, nosníveis de repouso eatividade, nos processos de sociabilidade ao longo do período de habituação ao ambientefísico e social da instituição.

\section{Consideraçõesfinais}

0 conjunto dos resultados revela que, na maioria dos casos analisados, há indícios de que as crianças encaminhadas à instituição não recebiam os cuidados adequados no meio familiar. A existência de crianças que chegaram ao abrigo desnutridas, doentes, com marcas físicas e emocionais dos maus-tratos sofridos na família evidencia um amplo leque de situações de negligência e abandono por parte dos pais e/ou responsáveis.

Com raras exceções, os documentos disponibilizados pelo abrigo revelam a preocupação de técnicos e autoridades com aspectos físicos e sociais que caracterizam o local de moradia da família de origem da criança. Em geral, são ambientes descritos como moradias precárias e insalubres, quase sempre habitadas por famílias de baixa renda, com a presença de pais e/ou responsáveis com poucos anos deestudo, o quetorna bastante difícil a tarefa de distinguir até onde vai a privação dos meios necessários à sobrevivência e ao bem-estar da família (nutrição, água, saneamento, saúde, moradia, educação) e onde começa realmente a reprodução de um padrão de cuidado presente há gerações, caracterizado por atitudes de negligência consigo, com o outro e o meio que o cerca.

$\mathrm{A}$ análise de registros referentes à prematuridade, baixo peso, intercorrências na gravidez e no parto, deficiências e distúrbios no desenvolvimento, permite constatar a existência de crianças que nasceram e estão crescendo em condições muito adversas e pouco saudáveis. Os resultados indicam que a pobreza e a fragilidade das bases de apoio à família colocam em risco a sobrevivência e a saúde da criança das mais diferentes formas, seja contribuindo para distúrbios e deficiências congênitas, seja impondo uma vida marcada por privações materiais e emocionais, como salientam Reichenheim e Harpham ${ }^{23}$.

Por sua vez, a proporção adulto/criança inadequada (1:8) ea superlotação do espaço (75/mês) são características ambientais que sugerem a configuração de situações de privação afetiva entre crianças já marcadas pelo signo da rejeição e do abandono.

Em razão disso, diversas costumam ser as dificuldades sentidas pelas crianças no período de adaptação à vida institucional. A freqüência de categorias como choro intenso e/ ou contínuo, retraimento social, comportamentos de agressividade e agitação descreve o quão podem ser diversos e graves os prejuízos para o desenvolvimento biopsicossocial da criança, especialmentequando a institucionalização ocorre por um tempo demasiadamentelongo.

É possível afirmar que, a partir do momento em que as crianças deram entrada na instituição, passaram a experimentar uma sobrecarga emocional que não pode ser minimizada, em função de duas situações consideradas muito estressantes: a privação da convivência com seus cuidadores primários e a adaptação às regras que regem a vida institucional ${ }^{10}$.

$\mathrm{Na}$ discussão dos resultados, outro aspecto merece também ser destacado. Conforme Maranhão ${ }^{24}$, a influência de fatores externos ao ambientefísico e social das instituições sobre os processos desaúde/doença na primeira infância tem sido discutida especialmente em trabal hos realizados em creches e pré-escolas. A maioria destaca a relação entre a alta incidência de doenças e outros riscos à saúde da criança em instituições infantis, eas variações climáticas (períodos de chuvas freqüentes, frio intenso, queda da umidade do ar), as condições socioeconômicas da família (características 
sócio-demográfica dos pais), a qualidade do cuidado oferecido pela família.

$M$ aranhão ${ }^{24}$, ao ouvir técnicos e educadores de instituições infantis, verificou queas condições materiais e emocionais no ambiente familiar são reconhecidas como elementos determinantes no processo de prevenção e tratamento de doenças, sendo consideradas até mais influentes que a própria qualidade do cuidado profissional que é oferecido à criança nesses espaços.

No caso específico da criança institucionalizada, entende-se que a situação pode ser ainda mais grave, na medida em que os abrigos não apenas representam espaços de cuidado diário como são as creches, mas assumem funções social mente atribuídas à família de maneira exclusiva e contínua 24 horas por dia. Essa característica, em particular, diferencia os abrigos de outras modalidades de cuidado coletivo e torna ainda mais complexo 0 sistema de atendimento nessas instituições.

Em função disso, torna-se fundamental que as instituições que promovem o cuidado infantil valorizem aspectos significativos das condições socioeconômicas em que vive a criança, além de dados referentes à estrutura, à composição, ao estilo de vida da família de origem, à rede social de apoio existente, ao modo como a criança tem sido assistida em suas necessidades essenciais ${ }^{25}$. Para esses pesquisadores, é preciso saber quem faz parte e como funciona a família da criança na promoção da saúde, sobretudo quando os cuidados infantis são compartilhados diariamente com outras pessoas ou instituições infantis.

No quadro dessa discussão, verifica-se que historicamente tem sido imputada à família a primazia no cuidado com os segmentos mais vulneráveis à doença, à incapacidade eà morte. N essa perspectiva, a família cumpre um papel decisivo na promoção da saúde de cada um de seus membros, mas especialmente da criança. Por essa razão, situações de risco, dificuldade ou crise vivenciadas pela família podem afetar de maneira decisiva as bases do seu desenvolvimento cognitivo, físico e sócioafetivo ${ }^{25}$.

Isso significa que, mesmo em condições deprivação material e emocional, os pais e/ou demais familiares são exigidos no sentido assegurar condições minimamente adequadas a um desenvolvimento saudável, devendo ocupar-se diretamente da rotina de cuidados que envolvem a alimentação, a higiene, o sono, a segurança física e emocional da criança.

Pelo exposto, entende-seser necessário o investimento em estudosque enfatizem mais a vida pregressa da criança que se encontra institucionaliza- da em abrigo, analisando com rigor aspectos relacionados tanto à qualidade do cuidado parental quanto às condições materiais de existência da família na promoção da saúde, sem que isso signifique reduzir a importância que as características ambientais das instituições destinadas ao cuidado infantil efetivamente têm para a compreensão dos processos de saúde/doença na primeira infância.

Do ponto de vista da ecologia do desenvolvimento humano, o nascimento sob o signo da pobreza e a convivência em meio à desagregação familiar, à violência e à drogadição são elementos constituintes do processo de socialização e marcam a formação da identidade da criança institucionalizada, tal qual compreende Bronfenbrenner ${ }^{8}$.

Asmarcas - nem semprevisíveis - de uma vida familiar passada em condições de privação material eemocional seguem com a criança atéo abrigo e ao longo do tempo são incorporadas ao contexto institucional, tornando-se presente nas relações que estabelece com seus cuidadores e pares, no modo como se insere no ambiente social, mas, sobretudo, na manifestação de doenças físicas e situações de sofrimento emocional que afetam 0 corpo e a mente.

Em consonância com o modelo teórico desenvolvido por Bronfenbrenner ${ }^{8}$, é possível analisar que essa experiência provoca pontos de convergência eintersecção entre dois contextos de desenvolvimento igualmente abrangentes em termos da atenção às necessidades essenciais da criança, mas que são intrinsecamente distintos em razão de características que Ihes são próprias.

De acordo com Bronfenbrenner ${ }^{8}$, são muitas as semelhanças e diferenças entre 0 lar familiar e a instituição infantil. Tanto a família como a instituição devem ser entendidas como contextos primários eabrangentes do desenvolvimento infantil. No entanto, épreciso seter um olhar atento às diferenças presentes nos subsistemas que, de maneiraintegrada, constituem o contexto ecológico do desenvolvimento humano. Para ele, os papéis, as atividades eas relações no microssistema familiar diferem bastantedaqueles encontrados em uma instituição. Em casa, os pais não são preparados para o exercício do cuidado infantil como uma atividade profissional efreqüentementecuidam de crianças em idades diversas. Já no microssistema institucional, as cuidadoras são profissionais e para-profissionais que compõem uma estrutura impessoal, com regras e horários que orientam o seu modo de trabalhar.

Sob essa perspectiva teórica, entende-se que a criança e a sua história de vida pessoal passam a fazer parte do contexto institucional sem que isso signifique o distanciamento e a ruptura com o le 
gado social e cultural que é característico do contexto familiar do qual deriva. Da mesma forma, a experiência do ajustamento à vida institucional, a forma específica decuidado profissional podem ensejar alterações no curso do desenvolvimento da criança, impactando negativamente sobre a aquisição de habilidades sociais, cognitivas e afetivas.

\section{Colaboradores}

LIC Cavalcante foi responsável pela estruturação e redação final do artigo, assim como pela análise e interpretação dos resultados; CM C M agalhães procedeu à orientação teórica e metodológica da pesquisa e à análise e discussão dos resultados; FAR Pontes orientou o trabalho de análise e discussão dos dados coletados.
Nesse sentido, aspectos do processo de saúde e doença da criança institucionalizada precisam ser vistos a partir da intersecção entre dois contextos de desenvolvimento nos quais fatores de riscos colocados à saúde física e emocional coexistem, exercem mútua influência e são potencializados em seus efeitos mais perversos.

\section{Referências}

1. Silva ERA. 0 direito à convivência familiar e comunitária: os abrigos para crianças e adolescentes no Brasil. Brasília: IPEA; 2004.

2. Silva AS, Reppold CT, Santos CL, Prade LT, Silva MR, Alves PB, Keller SH. Crianças em situação de rua de Porto Alegre: um estudo descritivo. Psicol. Reflex. Crit. 1998; 11(3):441-447.

3. Weber LND, Prado PM, Viezzer AP, Brandenburg OJ. Identificação de estilos parentais: o ponto de vista dos pais e dos filhos. Psicol. Reflex. Crit. 2004; 17 (3):323-331.

4. Cole M, Cole SR. 0 desenvolvimento da criança e do adolescente. Porto Alegre: Artmed; 2003.

5. Barker G, Rizzini I. Repensando o desenvolvimento infantil no contexto da pobreza no Brasil. 0 Social em Questão 2002; 7 (7):7-22.

6. Brazelton TB, Greenspan SI. As necessidades essenciais das crianças. 0 que toda criança precisa para crescer, aprender e se desenvolver. Porto Alegre: Artmed; 2002.

7. Yunes MAM, Miranda AT, Cuello SES. Um olhar ecológico para os riscos e as oportunidades de desenvolvimento de crianças e adolescentes institucionalizados. In: Koller SH, organizadores. Ecologia do desenvolvimento humano. Pesquisa e intervenção no Brasil. São Paulo: Casa do Psicólogo; 2004.

8. Bronfenbrenner U. A ecologia do desenvolvimento humano: experimentos naturais e planejados. Porto Alegre: Artmed; 1996.

9. Amorim KS, Yazlle C, Rosseti-Ferreira C. Binômios saúde-doença e cuidado-educação em ambientes coletivos de educação da criança pequena. Rev Bras Cresc Desenv Hum. 2000; 10(6):3-18.

10. Siqueira AC, Dell'Aglio DD. 0 impacto da institucionalização na infância e na adolescência: uma revisão da literatura. Psicol. Soc. 2006; 18 (3):71-80.

11. Fuchs SC, Maynart RC, Costa LF, Cardozo A, Schierholt R. Duration of day-care attendance and acute respiratory infection. Cad Saúde Pública 1996; 12 (3):291-296.

12. Costa JF. Ordem médica e norma familiar. $2^{a}$ ed. Rio de Janeiro: Graal; 1983.

13. Trindade JM B. $O$ abandono de crianças ou a negação do óbvio. Rev. Bras. Hist. 1999; 19(37):35-58. 
14. Rutília C. Los processos de desnutricion-infeccion en niños institucionalizados de las guarderias de la fundacion estadual de educacion al menor (FEBEM) en Rio de Janeiro [dissertação]. Rio de Janeiro (RJ): Escola Nacional de Saúde Pública; 1990.

15. Spitz RA. 0 primeiro ano de vida. São Paulo: Martins Fontes; 1998.

16. Bowlby J. Cuidados maternos e saúde mental. São PauIo: M artins Fontes; 1995.

17. Tizard $B, H$ odges J. The effects of early institutional rearing on the development of eight years old children. Journal of child psychology and psychiatry 1978; 19:99-118.

18. Weber LND, Kossobudzki LHM. Filhos da solidão. Institucionalização, abandono e adoção. Curitiba: Governo do Estado do Paraná; 1996.

19. Motta MAP. M ães abandonadas: a entrega de um filho em adoção. São Paulo: Cortez; 2001.

20. Papalia DE, OIds SW. D esenvolvimento humano. Porto Alegre: Artmed; 2000.

21. Carvalho A, Salles F, Guimarães M, Armond L. Saúde da Criança. Belo Horizonte: Editora UFM G/PROEX; 2003.

22. Rizzini I, Rizzini I. A institucionalização de crianças no Brasil: percurso histórico e desafios presentes. Rio de Janeiro: PUC-RJ/UNICEF/CIESPI; 2004.

23. Reichenheim ME, Harpham T. Perfil intracomunitário da deficiência nutricional: estudo de crianças abaixo de 5 anos numa comunidade de baixa renda do Rio de Janeiro. Rev. Saúde Pública 1990; 24(1):69-74.

24. Maranhão DG. 0 processo de saúde-doença e os cuidados com a saúde na perspectiva dos educadores infantis. Cad Saúde Pública 2000; 16 (4):1143-1148.

25. Ximenes LB, Pinheiro AKB, Lima KM, Nery HB. A influência dos fatores familiares e escolares no processo de saúde-doença da criança na primeira infância. Acta sci., Health sci 2004; 26(1):223-230.

Artigo apresentado em 26/10/2006

Aprovado em 27/06/2007

Versão final apresentada em 03/07/2007 